\title{
УДК 622.06 \\ ПРОИЗВОДСТВО ВЗРЫВНЫХ РАБОТ НА ЗАДАННЫЙ ГРАНУЛОМЕТРИЧЕСКИЙ СОСТАВ РУДЫ В РАМКАХ КОНЦЕПЦИИ «MINE-TO-MILL»: СОВРЕМЕННОЕ СОСТОЯНИЕ И ПЕРСПЕКТИВЫ
}

\author{
Маринин Михаил Анатольевич1, \\ marinin_ma@pers.spmi.ru
}

\author{
Евграфов Матвей Вячеславович 1 , \\ mevgrafov@mail.ru
}

\author{
Должиков Вадим Владимирович1, \\ dolzhikov_vv@pers.spmi.ru \\ 1 Санкт-Петербургский горный университет, \\ Россия, 199106, г. Санкт-Петербург, 21 линия, 2.
}

\begin{abstract}
Актуальность. Условия снижения содержания полезного компонента в руде, увеличения глубины отработки и уменьшения нераспределенного фонда месторождений обуславливают необходимость разработки эффрективных решений процесса «карьер-фабрика», которые должны быть адаптированы под каждое конкретное горное предприятие и позволят оптимизировать производственные затраты.

Целью исследования явилась разработка методологического подхода оценки влияния технологических фракторов на производственную цепочку формирования затрат от добычи до измельчения руды.

Объекты: золоторудные месторождения России, разрабатьваемые открытым способом.

Методы: анализ лучших технологических практик золотодобычи, включая анализ зарубежного и отечественного опыта организации процессов добычи и рудоподготовки; оценка влияния гранулометрического состава руды на технологические и эксплуатационные параметры и показатели работы выемочного оборудования карьера, дробильно-сортировочного комплекса и помольного оборудования золотоизвлекательной фабрики (производительность, анализ цикла, расхода электроэнергии и нормируемых материалов).

Результаты. Приведен обзор современного состояния вопроса производства буровзрывных работ на заданный гранулометрический состав в рамках концепции «тіne-to-тіll» для условий открытой разработки месторождений рудного золота. Научное исследование направлено на достижение максимальной производительности горнотранспортного оборудования карьера, дробильно-сортировочного комплекса и помольного оборудования золотоизвлекательной фрабрики. Это позволит не только получить стабильное качество извлекаемого сырья, оптимизировать расходы на дальнейшую рудоподготовку, но и повысить полноту извлечения полезного ископаемого в соответствии с принципами рационального недропользования. Исходя из опыта мировой практики производства буровзрывных работ, приведен комплекс рекомендательных мероприятий при подготовке и производстве взрывных работ на заданный гранулометрический состав руды в рамках концеnции «тіne-to-mill».
\end{abstract}

\section{Ключевые слова:}

Буровзрывные работы, mine-to-mill, гранулометрический состав взорванной горной массы, карьер, добыча рудного золота, оптимизация затрат.

\section{Введение}

Современное состояние открытой разработки рудных месторождений характеризуется ростом глубины карьера, повышением коэффициента вскрыши, снижением содержания полезных компонентов. При этом скорость подвигания забоев увеличивается вследствие высокой производительности оборудования.

Горнотранспортное оборудование становится все более грузоподъемным и более «прожорливым», при этом большая грузоподъемность оборудования эффективна только при максимальных значениях загрузки и коэффициента использования, что достигается при слаженной работе комплекса буровзрывные работы (БВР) - экскавация.

В данном случае рост производительности горного предприятия предполагает высокий КПД погрузочного оборудования. Основная задача БВР при этом направлена на достижение максимально эффективного использования основных средств за счет: качественного планирования, минимального воздействия взрыва на окружающий массив, формирования развала взорванной горной массы заданной формы и фрагментации.

В золотодобывающей промышленности эффективность перерабатывающих производств в наибольшей степени зависит от типа и физико-механических свойств добываемого сырья, что, в свою очередь, определяет способы организации и ведения добычных работ и рудоподготовки, применяемую технику и технологии.

В процессе разработки рудных участков золоторудных месторождений параметры технологии добычи, принятые при проектировании, могут не соответствовать варьирующимся физико-механическим свойствам руд, что на практике приводит к преждевременному износу оборудования, незапланированным ремонтам, недозагрузке перерабатывающих мощностей, росту эксплуатационных затрат на всех стадиях производственного процесса и снижению эффективности производства в целом. 
Поэтому оптимизация параметров технологических процессов, увязка технологической производительности и экономической эффективности с применением современных методов управления затратами является актуальной научной задачей.

Практика деятельности горнорудных предприятий, в том числе разрабатывающих золоторудные месторождения открытым способом, зачастую показывает отсутствие общей взаимосвязи энергозатрат технологических процессов карьера и золотоизвлекательной фабрики (ЗИФ). Это обусловливает необходимость выявления и анализа факторов, влияющих на параметры функционирования оборудования на добыче, экскавации, транспортировании, измельчении и обогащении, в разработке моделей оптимизации параметров работы оборудования во взаимосвязанных производственных процессах, в обосновании технологической и экономической эффективности выбранных организационно-технических решений с применением методов кост-инжиниринга [1].

\section{Концепция «mine-to-mill»}

Задача горного производства - оптимизировать всю технологическую цепочку этапов добычи и переработки полезных ископаемых, при этом в рамках решения задачи необходимо рассматривать каждый технологический процесс как отдельно, так и в комплексе. В зарубежной практике процесс оптимизации добычи и переработки носит название «mine-to-mill» (M2M). Например, компания Motion Metrics дает такое пояснение концепции М2M - это целостный подход к минимизации энергетических и эксплуатационных затрат при переработке полезного ископаемого путем оптимизации всех стадий процесса измельчения [2].

Концепция М2М формировалась начиная с 1990 гг., и в ее основе лежит задача эффективного объединения процессов добычи и обогащения на основе общей стоимости производства, а не на стоимости отдельных операций. B работах D. McKee [3] и P. Cameron [4] довольно полно описан зарубежный опыт развития концепции М2М. Отдельно стоит отметить исследования австралийских авторов [5-9]. Приведем на рис. 1 некоторые из направлений исследований M2M, условно разбив их на временные этапы.

B работе [3] D. McКее приводит технические шаги реализации проекта M2M, а также делает акцент на нетехнических факторах, которые также могут иметь решающее значение, - это поддержка со стороны руководства, наличие персонала со специальными навыками и благоприятная организационная структура работы.

Ранние исследования в большей степени были сосредоточены на оптимизации операций как отдельных частей или по определенному параметру. Как показали исследования специалистов Фрайбергской горной академии и Университета Миссури в Канзас-Сити [10], комплексная оптимизация в отличие от детерминистского подхода может быть более эффективна.

Оптимизация процессов горнодобывающего комбината в рамках концепции М2М дает результат по снижению на 7-22 \% общих затрат на бурение и взрывание, увеличению на 10-30 \% производительности дробильно-сортировочного комплекса, снижению на 17-31 \% себестоимости тонны руды. Оптимизация была реализована для условий золоторудных предприятий при привлечении таких консалтинговых компаний, как Esen Mining Consulting, под руководством S. Esen [11-13], Hatch и Metso PTI под руководством W. Valery, K.A. Duffy, A. Jankovic [14-16].

Разновидностью направления М2М является технология Pit-to-Plant (P2P), которая объединяет различные дисциплины геологии, горного дела, обогащения и металлургии с целью оптимизации процесса измельчения. В компании MorilaGoldMine (западная Африка) применение технологии Р2Р позволило увеличить производительность мельницы с 365 до 400 т/ч (примерно на 10 \% увеличение пропускной способности) с помощью цифрового онлайн анализа размера куска горной массы.

Исследования [3] установили, что значительная часть энергии (53\%), расходуемой на горном предприятии, направлена на измельчение руды на фабрике, в то время как всего $2 \%$ расходуется на БВР. Исходя из данного заключения, приведем несколько примеров эффективной оптимизации горного производства за счет незначительного увеличения энергозатрат на БВР.

В работах G. Brent [17, 18], L. Workman и J. Eloranta [19], специалистов компании Maxam [20] доказано, что увеличение производительности возможно за счет большей энергии взрыва и, как следствие, уменьшения размера куска при питании мельницы и сокращения энергозатрат на измельчение. Так, компания Orica на золотодобывающем карьере MtRawdon (Австралия) для увеличения производительности предприятия внедрила высоэнергетичекие взрывчатые вещества [21]. MtRawdon добывает руду с низким содержанием золота (0,71-1,0 г/т). В 2014 г. компания начала поиск возможностей по увеличению производительности мельниц без значительных капитальных затрат и модификации существующего оборудования обогатительной фабрики. Анализ показал, что значительное влияние на производительность мельниц оказывает тип руды - расхождение достигало 30 \% для различных типов руд. На основе данного анализа были выявлены две первоочередные цели: увеличить содержание руды класса минус 13 мм при питании мельницы и уменьшить объем руды, попадающий на рециркуляцию.

На участках карьера с наиболее крепкими породами был проведен ряд опытных взрывов с увеличенным в 2 раза удельным расходом штатного ВВ. Увеличенное воздействие взрыва на массив привело к появлению негабаритов по периметру блока и переизмельчению в ближней зоне дробления, итого снижение производительности мельницы на 4 т/ч. Также сложные горные условия и ограниченность парка бурового оборудования означало неприемлемость сужения сетки скважин. В данном случае стандартный подход увеличения удельного расхода ВВ не работает! 


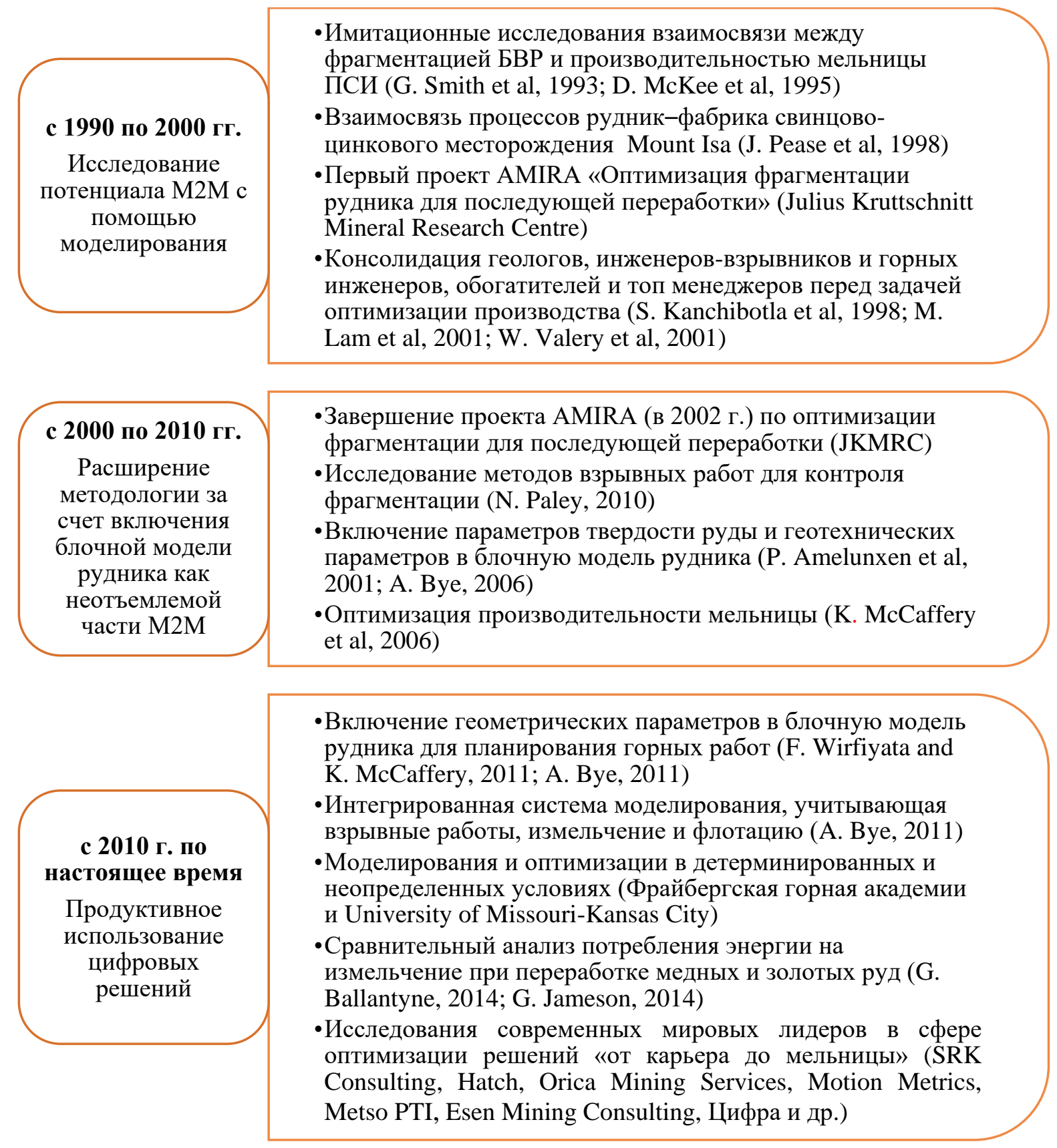

Puc. 1. Этапь развития концепциии М2M

Fig. 1. Stages of development of the M2M concept

Внедрение высокоэнергетических непатронированных эмульсионных взрывчатых веществ позволило решить данную задачу. При плотности ЭВВ 1,35 г/см ${ }^{3}$ энергия взрыва на $55 \%$ выше без изменения параметров БВР. Экспериментальные блоки взрывались парно с блоками со стандартным типом ВВ и оценивались по следующим показателям эффективности: фрагментационный состав, производительность экскаватора, производительность мельницы (т/ч), потребление электроэнергии (кВт/т). В результате, в зависимости от типов пород, сетка скважин была увеличена на 45-60 \% без последующего снижения производительности экскавации; парк буровых станков был сокращен с 4 до 3 единиц; производительность мельницы увеличилась на 5,9 \%; потребление элек- троэнергии мельницей сократилось на 7,3 \%; количество рециркуляционного продукта ПСИ сократилось с 17,4 до $13,8 \%$.

Классический пример увеличения удельного расхода ВВ в рамках опытно-промышленных испытаний и последующего моделирования представлен в работе [22]. Увеличение колонки заряда ВВ или сближение сетки скважин, изменение угла инициирования или интервалов поверхностных замедлений бывают достаточными операциями для улучшения количественного выхода заданной фракции.

Еще один пример оптимизации - применение современных электрических детонаторов с программируемым электронным замедлением для поддержания заданного гранулометрического состава [23]. Так, 
применяя электронные детонаторы, карьер по добыче известняка Nongtarai в Индии смог увеличить производительность дробильного оборудования и снизить затраты на БВР. За счет подбора соответствующих замедлений между скважинами удалось снизить выход негабарита на $13 \%$. Выход кондиционной фракции составил $83 \%$ от объема взорванной горной массы вместо $70 \%$, ранее получаемых в результате применения неэлектрических систем инициирования.

Трудами отечественных ученых были заложены основы и в настоящее время учениками продолжается совершенствование решений одной из главных проблем горного производства - обеспечение равномерного и качественного дробления горных пород взрывом. Значительный вклад в развитие методов определения параметров буровзрывных работ на заданный гранулометрический состав взорванной горной массы внесли: на основе деформационного зонирования взрываемых уступов [24], для сложноструктурных массивов горных пород [25-28], на основе инвариантов процесса дробления горных пород (Ю.И. Виноградов), на основе сопряжения зон разрушения (М.Г. Менжулин) и многие другие.

В 1970-1980-х гг. под руководством И.А. Тангаева [29] на базе накопленного объема данных по энергоемкости процессов бурения, взрывания и экскавации на карьерах Калмакырском, Кургашинканском, Коунрадском и Саяк-1, их статистической и графической обработки установлено, что величина удельной энергоемкости шарошечного бурения взрывных скважин позволяет осуществлять количественную оценку буримости горных пород, определять их взрываемость (с коэффициентом корреляции 0,8-0,9) и даже прогнозировать энергоемкость процесса экскавации с корреляцией 0,6-0,7. Были получены первые математические зависимости для обоснованного расчета удельного расхода и «сетки» взрывных скважин. В результате наметилось решение одной из самых сложных задач в технологии открытых горных работ - расчета и выбора параметров БВР с учетом пространственной неоднородности горных пород в пределах технологических блоков и месторождения в целом.

В 1989 г. в журнале «Mining Science and Technology» в статье професcopa C.O. Brawner из Университета Британской Колумбии [30] излагались результаты исследований во многом аналогичные результатам И.А. Тангаева. Канадские ученые пришли к аналогичным выводам, проведя оценку буримости и взрываемости горных пород по удельным затратам энергии в процессе бурения, при этом одни из первых в исследованиях в горном деле применили электронно-вычислительную технику (устройство регистрации расхода энергии, основанное на использовании процессора Z80).

В дальнейшем мощный задел исследований по энергоемкости процессов добычи позволил группе киргизских специалистов разработать прибор, предназначенный для сбора и первичной обработки данных с буровых станков [31, 32]. Контроллер бурового станка «Кобус» был испытан на высокогорном золо- торудном карьере Кумтор. На основании успешных испытаний был разработан программно-технический комплекс САПР БВР «Blast Maker». Таким образом, реализован принцип проектирования БВР на основе оперативной информации о взрываемости пород. Экономический эффект при этом выражается в снижении затрат на комплекс БВР до 10 \% и повышении производительности горнотранспортного оборудования до $8 \%[33,34]$.

В зарубежной практике измерения во время бурения носят название «measurement while drilling» (MWD). Исследования [35, 36] доказывают, что практика внедрения MWD позволяет наиболее качественно подготавливать массив к взрыву на заданную фрагментацию.

Таким образом, качество взрывной подготовки горных пород к выемке оказывает влияние на экономические показатели всех технологических процессов горнодобывающего предприятия, причем влияние для различных технологических процессов будет различным. На основе трудов Ю.И. Виноградова [37, 38] можно подчеркнуть вывод, что существует такой оптимальный гранулометрический показатель взорванной горной массы, который для определенной технологической схемы горнодобывающего предприятия обеспечивает минимальную себестоимость добычи полезного ископаемого.

\section{Обсуждение}

На основе анализа данных горнодобывающих предприятий, разрабатывающих месторождения рудного золота открытым способом в условиях Крайнего Севера на рис. 2 приведены усредненные соотношения удельных затрат по основным технологическим операциям на $1 \mathrm{~m}^{3}$ рудной массы. На долю БВР приходиться порядка 8-12 \% от всех затрат. Затраты на взрывание выше затрат на бурение. На рис. 3 приведены удельные затраты по проведению взрывных работ. Основная доля затрат приходится на взрывчатое вещество. На средства инициирования и боевики приходиться до $10 \%$ затрат, при этом они играют значительную роль в формировании заданной фрагментации и соответственно влияют на эффективность последующих процессов, что подтверждается исследованиями [39]. Также, например, незначительные локальные увеличения затрат на применение зарядных рукавов [40], производство качественной забойки, шахматной схемы бурения и прочее позволяют достичь значительных сокращений энергозатрат при последующем переделе рудного компонента.

Для условий открытых горных работ месторождений Олимпиадинское, Благодатное и Вернинское группы компаний «Полюс» специалистами международной консалтинговой фирмы Hatch за текущие несколько лет проделана большая работа по увеличению производительности и повышению эффективности технологических процессов «от карьера до фабрики». Проведены исследования, включающие изучение характеристик руды, аудит технологических процессов, анализ данных, моделирование, расчет мощности мельницы (Morrell), опыт эксплуатации и ана- 
лиз затрат были использованы для выявления возможностей увеличения производства (пропускной

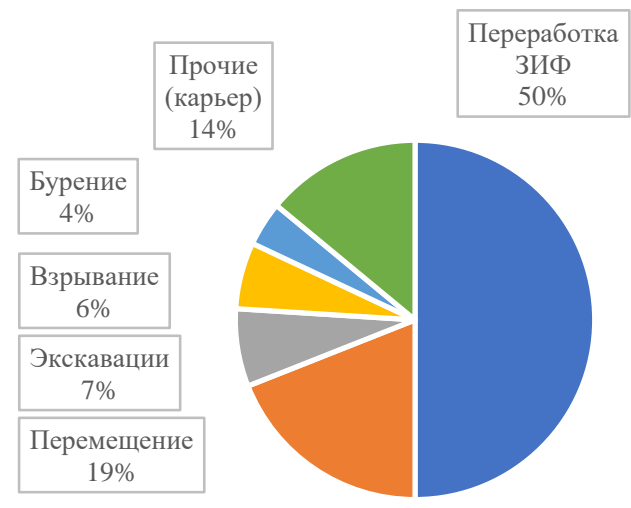

Pис. 2. Структура удельных затрат по основнылм технологическим операциям на $1 \mathrm{~m}^{3}$ рудной массы

Fig. 2. Structure of unit costs for the main technological operations per $1 \mathrm{~m}^{3}$ of ore mass

Исходя из опыта мировой практики производства буровзрывных работ, в том числе лидеров отрасли компании Оrica и Махат, применения современных средств измерения параметров, использования программных продуктов для моделирования процессов и проектирования параметров буровзрывных работ ниже приводим рекомендованный комплекс мероприятий при подготовке и производстве БВР на заданный гранулометрический состав руды в рамках концепции М2М (рис. 4).

Что касаемо электронных систем инициирования, то в настоящее время горная промышленность России активно внедряет более точные электронные программируемые детонаторы [39, 43-47] и не только для минимизации сейсмовоздействия, а также для улучшения качества фрагментации. Так, лидерами по применению детонаторов с электронным программируемым устройством являются Кузбасские угольные разрезы. В золоторудной отрасли в последние годы проведены значительные исследования по влиянию электронных систем инициирования, а именно их точности срабатывания и вариативности шага замедления, на качество выхода гранулометрического состава взорванной рудной массы.

Из практики взрывного дела мы знаем, что вариативная (заводская) ошибка срабатывания систем НСИ может доходить до $10 \%$ от номинала замедления [48-51]. И инженерам проектировщикам невозможно предугадать, в каком детонаторе и как поведет себя пиротехническое вещество, при этом ошибка может быть как в поверхностном, так и в скважинном капсюле.

Поэтому для условий горных работ, где точность срабатывания и вариативность замедлений значительно влияет на качество гранулометрического состава руды, внедрение современных систем иниции- способности и извлечения) при минимизации затрат и энергопотребления на тонну концентрата [41, 42].

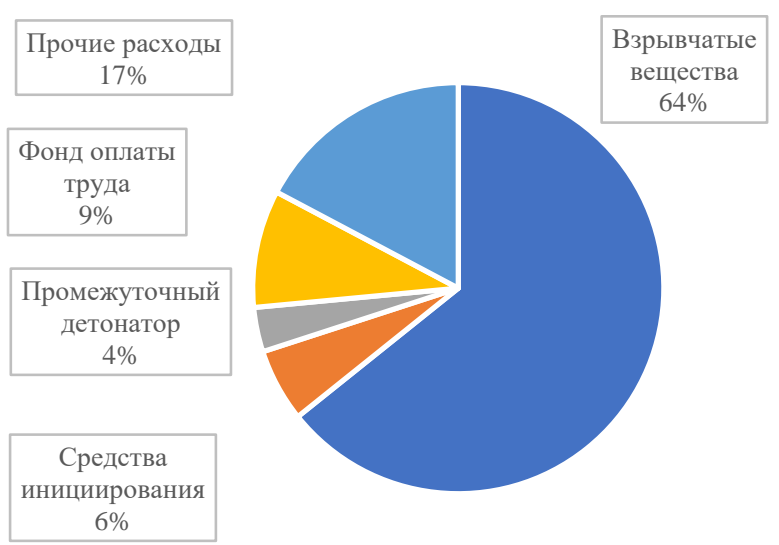

Pис. 3. Структура удельных затрат при производстве взрывных работ

Fig. 3. Structure of unit costs in production of blasting operations

рования неизбежно. Для российского рынка это аналогично вытеснению электрического взрывания и детонирующих шнуров неэлектрическими системами инициирования типа «Нонель». Главный сдерживающий фактор сейчас - это стоимость электронного детонатора, как отечественного производства (Искра), так и импортного (I-kon, Daveytronic). Доля применения данных систем инициирования некоторыми горными компаниями Австралии, Латинской и Северной Америки достигает $80 \%$, при этом стоимость применения детонатора ЭСИ к НСИ - 4/1. Для российского рынка это соотношение доходит до 20/1.

\section{Заключение}

По данным Минфина производство золота в России за 2019 г. составило 343,54 т (2018 - 314,42 т), и в ближайшей перспективе данный показатель будет только увеличиваться. Приведем некоторые новые проекты крупнейших золотодобывающих компаний Росси до 2025 г. Так, в планах лидера отрасли нарастить объемы добычи и переработки руд месторождения Благодатное (Северо-Енисейский район, Красноярский край) до 17 млн т руды в год (в настоящее время 9 млн т). Также на одном из крупнейших месторождений мира Сухой Лог (Бодайбинский район, Иркутская область) уже на финальной стадии геологоразведочные работы и технико-экономическое обоснование проекта. К 2022 г. планируется выход на производственную мощность ГОК четвертого по величине месторождения золота в России Нежданинское (Республика Саха-Якутия). Строительство ГОКа для месторождения Высокое (Северо-Енисейский район, Красноярский край) и выход его на проектную мощность планируется в 2023 г. Таким образом, ближайшая перспектива развития золоторудной отрасли Росси выглядит достаточно уверенно. 


\begin{tabular}{|c|}
\hline Районирование карьерного поля по взрываемости \\
\hline $\begin{array}{l}\text { •Сбор и анализ данных по трещиноватости, крепости горных пород и } \\
\text { залеганию рудных тел } \\
\text { •Применение экспресс методов определения блочности взрываемого массива } \\
\text { (Sirovision) } \\
\text { •Применение экспресс методов на испытание точечной нагрузки (PLT) } \\
\text { •Районирование по энергоемкости во время бурения } \\
\text { •Постоянная актуализация цифровой модели карьера по взрываемости }\end{array}$ \\
\hline Проектирование массового взрыва \\
\hline $\begin{array}{l}\text { •Оценка поверхности подготавливаемого массива } \\
\text { •Лазерное профилирование откоса уступа для четкого определения выноски } \\
\text { первого ряда взрывных скважин } \\
\text { •Подбор конструкции заряда и интервалов замедлений } \\
\text { •Оконтуривание рудных тел по сортовым показателям } \\
\text { •Определение оптимального соотношения расстояния между рядами и } \\
\text { скважинами в ряду } \\
\text { •Применение высоэнергетических ВВ } \\
\text { •Примение узкоспециализированных программных продуктов для задач БВР } \\
\text { (ShotPlus, I-Blast, BMM Explorer, BLADES, RIOBLAST, Геомикс Развал) }\end{array}$ \\
\hline
\end{tabular}

\begin{tabular}{|c|c|}
\hline Средства и схемы инициирования & \\
\hline \multicolumn{2}{|c|}{$\begin{array}{l}\text { •Применение боевиков со скоростью детонации и теплотой взрыва большей, } \\
\text { чем у штатных ВB }\end{array}$} \\
\hline $\begin{array}{l}\text { •Применение электронных детонаторов, исключающих } \\
\text { срабатывания и увеличивающих вариативность схем замедлениі }\end{array}$ & погрешность \\
\hline
\end{tabular}

Контроль качества до взрыва
•Оценка качества пробуренных скважин (инклинометрия, глубина)
•Оценка качества зарядки скважин (размещение боевика, масса ВВ)
•Производство забойки (оптимальныл размером забоечного материала
считается щебень размером 10-15\% от диаметра скважсины)

Контроль качества после взрыва
•Оценка параметров развала взорванной рудной массы
• Мониторинг взорванной рудной массы методом фотопланометрии при
экскавации в ковше экскаватора или на стадии транспортирования в кузове
автосамосвала/по ленте конвейера (РоwerSieve, PortaMetrics, WipFrag)
• Оценка времени цикла работы оборудования, занятого при экскавации
• Оценка степени износа рабочих органов оборудования, занятого на экскаваци
•Оценка производительности дробильного и помольного оборудования

Рис. 4. Мероприятия при подготовке и производстве БВР на заданный гранулометрический состав руды в рамках кониеепции $\mathrm{M2M}$

Fig. 4. Measures in preparation and production of blasting operations for a given ore grain size composition within the framework of the $M 2 M$ concept

При этом на стадии проектирования открытой разработки новых месторождений рудного золота России, в том числе приведенных выше, целесообразно учитывать опыт комбинатов, прошедших путь оптимизации технологических процессов в рамках кон- цепции «M2M». Проектные решения уже должны учитывать комплекс мероприятий, направленных на производство БВР на заданный гранулометрический состав руды для конкретных горно-геологических условий вновь разрабатываемого месторождения. 
Именно качественно подготовленный и проведенный комплекс БВР, как начальный технологический процесс, определяет энергоемкость всех последующих процессов передела рудной массы. Сегодня горные предприятия пришли к понимаю, что стремление к оптимизации отельных технологических процессов (таких как бурение, взрывание, экскавация и далее) не всегда приводит к оптимизации комплекса рудного передела в целом.

\section{Выводы}

В данной работе приведен обзор современного состояния вопроса производства буровзрывных работ на заданный гранулометрический состав в рамках концепции «mine-to-mill» для условий открытой ра3работки месторождений рудного золота. Научное исследование направлено на достижение максимальной производительности горнотранспортного оборудования карьера, дробильно-сортировочного комплекса и помольного оборудования золотоизвлекательной фабрики. Это позволит не только получить стабильное качество извлекаемого сырья, оптимизировать расходы на дальнейшую рудоподготовку, но и повысить полноту извлечения полезного ископаемого в соответствии с принципами рационального недропользования. Ниже приведены основные выводы: 1. В условиях работы горно-обогатительного комбината существует оптимальный кусок взорванной рудной массы, обеспечивающий минимальные

\section{СПИСОК ЛИТЕРАТУРЫ}

1. Marinina O., Nevskaya M. Cost management of mining project life cycle // International Multidisciplinary Scientific GeoConference Surveying Geology and Mining Ecology Management, SGEM. - Sofia Bulgaria, 2017. - V. 17 (13). - P. 175-179.

2. Mine-to-mill optimization // Motion Metrics. URL: https://www.motionmetrics.com/mine-to-mill-optimization/ (дата обращения: 01.10.2020)

3. McKee D. Understanding mine to mill. - Brisbane Australia: Cooperative research centre for optimising resource extraction, 2013. $-96 \mathrm{p}$.

4. Cameron P., Drinkwater D., Pease J. The ABC of Mine to Mill and metal price cycles // Proc. $13^{\text {th }}$ AusIMM Mill Operators' Conference. - Melbourne: The Australasian Institute of Mining and Metallurgy, 2016. - P. 349-358.

5. An integrated geology-mine-plant and eco-efficiency simulator for anglo platinum's evaluation and operational improvement initiatives / M. Ziemski, A. Bye, N. Plint, M. Cole, A. Tordoir // XXV International Mineral Processing Congress. - Brisbane, 2010. V. 5. - P. 3629-3638.

6. Bye A. The strategic and tactical value of a 3D geotechnical model for mining optimization, Anglo Platinum, Sandsloot open pit // Journal of the Southern African Institute of Mining and Metallurgy. - 2006. - V. 106. - № 2. - P. 97-104.

7. Integration and optimisation of Blasting and Comminution Processes / S. Esen, D. LaRosa, A. Dance, W. Valery, A. Jankovic / EXPLO. - Australia, 2007. - P. 95-103.

8. Ballantyne G.R., Powell M.S. Benchmarking comminution energy consumption for the processing of copper and gold ores // Minerals Engineering. - 2014. - V. 65. - P. 109-114.

9. Curry J.A., Ismay M.J.L., Jameson G.J. Mine operating costs and the potential impacts of energy and grinding // Minerals Engineering. - 2014. - V. 56. - P. 70-80.

10. Optimized design of drilling and blasting operations in open pit mines under technical and economic uncertainties by system dynamic modelling / H. Abbaspour, C. Drebenstedt, M. Badroddin, энергозатраты при его экскавации, транспортировании, вторичном дроблении и последующем фабричном переделе.

2. Анализ эноргозатрат технологических процессов открытой разработки месторождений рудного золота (буровзрывная подготовка к выемке, экскавация и измельчение на ДСК и ЗИФ) при различных вариациях гранулометрического состава исходной руды позволяет определить оптимальный кусок взорванной рудной массы, обеспечивающий минимальные удельные энергозатраты при его переделе.

3. Накопленный мировой опыт, современные средства измерения, проектирования и моделирования позволяют обеспечить ведение буровзрывных работ на заданный гранулометрический состав в конкретных горно-геологических условиях открытой разработки месторождений рудного золота.

4. Для оценки эффективности работы технологических процессов горно-обогатительного комбината требуется постоянный гранулометрический контроль взорванной рудной массы на всех этапах передела.

5. На стадии проектирования горно-обогатительного комплекса вновь разрабатываемых месторождений рудного золота России целесообразно учитывать опыт комбинатов, прошедших путь оптимизации технологических процессов в рамках концепции « $\mathrm{M} 2 \mathrm{M} »$.

A. Maghaminik // International Journal of Mining Science and Technology. - 2018. - V. 28. - P. 839-848.

11. Esen S. Fragmentation modelling and the effects of ROM fragmentation on comminution circuits // $23^{\text {rd }}$ International Mining Congress \& Exhibition. - Turkey, 2013. - P. 252-260.

12. Esen S. Evaluating the fragmentation data from copper and gold mines // $43^{\text {rd }}$ Annual Conference on Explosives \& Blasting Technique. - Florida, 2017. - P. 1-13.

13. Improving final wall and waste blasting results at altynalmas pustynnoye gold mine / B. Bachramov, B. Myrzakasymov, A. Kalmatayev, S. Esen // IMCET 2019 - Proceedings of the $26^{\text {th }}$ International Mining Congress and Exhibition. - Turkey, 2019. P. 391-398.

14. Bulk ore sorting cut-off estimation methodology: Phu Kham Mine case study / A. Reple, A.C. Chieregati, W. Valery, F. Prati // Minerals Engineering. - 2020. - V. 149. - P. 1-4.

15. Techno-economic evaluation of bulk ore sorting for copper ore at the panaust phu kham operation / W. Valery, K. Duffy, P. Holtham, A. Reple, P. Walker, P. Rosario // IMPC $2016-28^{\text {th }}$ International Mineral Processing Congress. - Canada, 2016. - P. 1-11.

16. Valery W., Rybinski E. Optimization process at antamina boosts production and energy efficiency // Engineering and Mining Journal. - 2015. - V. 213. - P. 116-120.

17. Ultra-high-intensity blasting - a new paradigm in mining / G.Brent, P. Dare-Bryan, S. Hawke, M. Rothery // AusIMM Bulletin. 2014. - V. 5. - P. 395-400

18. Ultra-high intensity blasting for improved ore comminution / G.F. Brent, M.D. Rothery, P.C. Dare-Bryan, S.J. Hawke, R. Gomez, I. Humeres // Proc. of the $10^{\text {th }}$ International Symposium on Rock Fragmentation by Blasting. - India, 2013. - P. 163-169.

19. Workman L., Eloranta J. The effects of blasting on crushing and grinding efficiency and energy consumption // Proc. of the Annual Conference on Explosives and Blasting Technique. - USA, 2003. - P. 131-140.

20. Couceiro P., Santos B. The influence of blasting energy factor on the loading performance // International journal of engineering research \& technology (IJERT). - 2019. - V. 8. - P. 731-734. 
21. Wallace G., Morton D. High energy bulk explosives and mine to mill focus - the Mt Rawdon Story // Proc. Ninth AusIMM Open Pit Operators' Conference. - Australia, 2016. - P. 60-69.

22. Using process integration \& optimization to provide integrated process solutions for mining operations, from mine to mill / E. Isokangas, W. Valery, A. Jankovic, B. Sönmez // $26^{\text {th }}$ International Mineral Processing Congress. - India, 2012. - P. 2224-2234

23. Сафронов М. Uni Tronic ${ }^{\mathrm{TM}}$ для БВР. Как сделать буровзрывные работы более эффективными // Журнал Глобус. - 2020. T. 60 . - C. $180-182$.

24. Кузнецов В.А. Прогнозирование грансостава взорванной массы на основе структурно-деформационного зонирования взрываемых полигонов // Взрывное дело. - 2001. - Т. 93. C. $47-55$.

25. Белин В.А., Потресов Д.К., Сапожников С.И. Оптимизация показателей производства взрывных работ на карьерах // Горный информационно-аналитический бюллетень. - 2007. № S7. - C. 89-97.

26. Эквист Б.В. Оптимизация взрывных работ при разрушении неоднородных массивов // Горный информационноаналитический бюллетень (научно-технический журнал). 2017. - № 2. - C. 376-383.

27. Рахманов Р.А. Совершенствование технологии буровзрывных работ при дроблении разнопрочных горных массивов // Горный информационно-аналитический бюллетень (научнотехнический журнал). - 2015. - № S1-1. - С. 453-465.

28. Норов Ю.Д., Бибик И.П., Заиров Ш.Ш. Управление эффективными параметрами буровзрывных работ по критерию качества взорванной горной массы // Известия высших учебных заведений. Горный журнал. - 2016. - № 1. - С. 87-93.

29. Тангаев И.А. Буримость и взрываемость горных пород. - М. Недра, 1978. - 184 c.

30. Ringwald J.P., Brawner C.O. Reinforcing concrete model pillars with grouted rock bolts // Mining Science and Technology. 1989. - V. 8. - P. 31-47.

31. Коваленко В.А., Тангаев И.А. Энергетический принцип контроля и оптимизации технологических процессов на карьерах // Горный информационно-аналитический бюллетень. - 2008. T. 10. - C. 293-301.

32. Коваленко В.А. Автоматизированная подготовка производства на карьерах // Вестник КРСУ. - 2009. - Т. 9. - № 11. C. $118-123$.

33. Современные информационные технологии в подготовке и проведении БВР на угольных разрезах СУЭК / В.Б. Артемьев, В.Б. Коваленко, В.А. Артемьев, П.И. Опанасенко, А.Б. Исайченков // Уголь. - 2012. - № 11. - С. 6-13.

34. Опанасенко П.И., Исайченков А.Б. Результаты применения програмно-технологического комплекса «Blast Maker» для проектирования параметров БВР на разрезе «Тугнуйский» // Горный информационно-аналитический бюллетень (научнотехнический журнал). - 2013. - Т. 2. - С. 38-57.

35. Isheyskiy V., Sanchidrián J.A. Prospects of applying MWD technology for quality management of drilling and blasting operations at mining enterprises // Minerals. - 2020. - V. 10. P. $1-17$.

36. Application of drill-monitoring for chargeability assessment in sublevel caving / J. Navarro, H. Schunnesson, R. Ghosh, P. Segarra, D. Johansson, J.Á Sanchidrián. // International Journal of Rock Mechanics and Mining Sciences. - 2019. - V. 119. - P. 180-192.

37. Виноградов Ю.И. Инвариантный метод расчета параметров БВР на заданный гранулометрический состав взорванной горной массы // Кременчук. - 2010. - Т. 5. - С. 97-107.
38. Определение оптимальной степени дробления при переходе на циклично-поточную технологию в условиях Оленегорского ГОКа / Ю.И. Виноградов, И.Н. Гринберг, В.П. Макарьев, В.Г Прокопова, Е.А. Деев // Горный журнал. - 1976. - С. 28-31.

39. Белин В.А., Горбонос М.Г., Митков В.Е. Влияние качества взрывчатых веществ и средств инициирования на эффективность дробления горной массы взрывом // Горный информационно-аналитический бюллетень. - 2016. - № S1 - - С. 72-80.

40. Оверченко М.Н., Толстунов С.А., Мозер С.П. Влияние горногеологических условий и техногенных факторов на устойчивость взрывных скважин при открытой разработке апатитнефелиновых руд // Записки Горного Института. - 2018. T. 231. - C. 239-244.

41. Increasing production at polyus gold Blagodatnoye with holistic optimization from mine-to-plant / A. Tokarenko, I. Timofeyev, S. Kilin, W. Valery, R. Valle, K. Duffy // Procemin 2017: $13^{\text {th }}$ International Mineral Processing Conference. - Chile, 2017. P. 1-9.

42. Improving profitability, sustainability and the overall operating efficiency from mine to process in Russian operations / W. Valery, K. Duffy, R. Faveere, R. Hayashida, A. Jankovic, E. Tabosa, I. Yelkin // IMPC $2018-29^{\text {th }}$ International Mineral Processing Congress. - Russia, 2018. - P. 1346-1354.

43. Беляев А. Г, Набиулин М. Ф. Опыт работы ООО «АзотЧерниговец»: применение систем электронного взрывания «DAVEYTRONIC» на горнодобывающих предприятиях // Уголь. - 2013. - № 10. - С. 4-6.

44. Кондратьев А.С., Мартынушкин Е.А., Баженов В.Е. Опыт применения электронных детонаторов ЭДЭЗ-с в условиях ООО «Ресурс» и ООО «Инвест-Углесбыт» // Взрывное дело. 2020. - № 129-86. - C. 105-115.

45. Масаев Ю.А., Доманов В.П. Электродетонаторы с электронным замедлением (опыт промышленного применения) // Вестник Кузбасского государственного технического университета. - 2010. - № 2 (78). - С. 102-106.

46. О перспективных направлениях использования экспериментальных данных сейсмо-деформационного мониторинга в буровзрывных работах на карьерах / В.Н. Опарин, В.Ф. Юшкин, А.Н. Гришин, А.В. Богатырев, Н.Н. Пороховский, Д.Е. Рублев // Горный информационно-аналитический бюллетень (научнотехнический журнал). - 2019. - № 7. - С. 104-122.

47. Современные средства инициирования АО «НМЗ "Искра"»/ С.А. Кондратьев, С.А. Поздняков, А.С. Иванов, К.А. Вандакуров // Взрывное дело. - 2019. - № 123-80. - С. 136-143.

48. Новые технологии ведения взрывных работ / В.А. Белин, М.Г. Горбонос, С.К. Мангуш, Б.В. Эквист // Горный информационно-аналитический бюллетень (научно-технический журнал). - 2015. - № S1. - С. 87-102.

49. Белин В.А., Горбонос М.Г., Астахов Е.О. Влияние средств инициирования на эффективность и безопасность взрывных работ // Горный журнал. - 2017. - № 7. - С. 63-67.

50. Сысоев А.А., Кондратьев С.А., Катанов И.Б. Сравнительная оценка пиротехнических и электронных капсюлейдетонаторов на основе вероятностной модели инициирования системы скважинных зарядов // Взрывное дело. - 2020. № 126-83. - C. 85-98.

51. Оптимизация параметров взрывных работ увеличением интервалов замедления / Ю.А. Митюшкин, Ю.А. Лысак, А.Ю. Плотников, А.В. Ружицкий, Е.Б. Шевкун, А.В. Лещинский // Горный информационно-аналитический бюллетень (научно-технический журнал). - 2015. - № 4. - С. 341-348.

Поступила 26.04.2021 2.

\section{Информация об авторах}

Маринин М.A., кандидат технических наук, доцент кафедры взрывного дела Санкт-Петербургского горного университета.

Eвграфов М.B., аспирант, Санкт-Петербургский горный университет.

Должиков В.В., кандидат технических наук, доцент кафедры взрывного дела Санкт-Петербургского горного университета. 
UDC 622.06

\title{
PRODUCTION OF BLASTING OPERATIONS FOR A GIVEN GRANULOMETRIC COMPOSITION OF ORE WITHIN THE FRAMEWORK OF THE «MINE-TO-MILL» CONCEPT: CURRENT STATE AND PROSPECTS
}

\author{
Mikhail A. Marinin'1, \\ marinin_ma@pers.spmi.ru
}

\author{
Matvey V. Evgrafov' 1 , \\ mevgrafov@mail.ru \\ Vadim V. Dolzhikov', \\ dolzhikov_vv@pers.spmi.ru \\ 1 Saint-Petersburg Mining University, \\ 2, 21 line, St. Petersburg, 199106, Russia.
}

Relevance. The conditions for reducing the content of the valuable component in the ore, increasing the depth of mining and reducing the unallocated fund of deposits induce the necessity of development of effective solutions for the «mine-to-mill» process, which must be adapted for each specific mining enterprise and will optimize production costs.

The aim of the study was to develop a methodological approach to assess the influence of technological factors on the production chain of cost formation from mining to grinding ore.

The objects of the research are open-cut gold deposits in Russia.

Methods: analysis of the best technological practices of gold mining, including the analysis of foreign and domestic experience in organizing mining and ore preparation processes; impact assessment of the particle size distribution of ore on the technological and operational parameters and performance of the mining equipment in the open pit, crushing and screening complex and grinding equipment of the gold processing plant (productivity, cycle analysis, energy consumption and standard materials).

Results. We provide an overview of the current state of the issue of drilling and blasting operations for a particle size distribution within the «mine-to-mill» concept for the conditions of opencast mining of ore gold. Scientific research is focused on achieving maximum productivity of the mining and conveyor equipment of the quarry, the crushing and screening complex and the grinding equipment of the gold processing plant This will allow not only obtaining a stable quality of recovered raw materials, optimizing the costs of further ore preparation, but also increasing the recovery ratio according to the principles of sustainable subsurface use. Basing on the experience of world practice in the production of drilling and blasting operations, we provide blasting design recommendations for a target particle size distribution within «mine-to-mill» concept.

\section{Key words:}

Drilling and blasting, mine-to-mill, particle size distribution, quarry, mining of ore gold, cost optimization.

\section{REFERENCES}

1. Marinina O., Nevskaya M. Cost management of mining project life cycle. International Multidisciplinary Scientific GeoConference Surveying Geology and Mining Ecology Management, SGEM. Bulgaria, 2017. Vol. 17, pp. 175-179.

2. Mine-to-mill optimization. Motion Metrics. Available at: https://www.motionmetrics.com/mine-to-mill-optimization/ (accessed: 1 October 2020)

3. McKee D. Understanding mine to mill. Brisbane Australia, Cooperative research centre for optimising resource extraction, $2013.96 \mathrm{p}$.

4. Cameron P., Drinkwater D., Pease J. The ABC of Mine to Mill and metal price cycles. Proceedings 13th AusIMM Mill Operators' Conference. Melboume, The Australasian Institute of Mining and Metallurgy, 2016. pp. 349-358.

5. Ziemski M., Bye A., Plint N., Cole M., Tordoir A. An integrated geology-mine-plant and eco-efficiency simulator for anglo platinum's evaluation and operational improvement initiatives. XXV International Mineral Processing Congress. Brisbane, 2010. Vol. 5, pp. 3629-3638.

6. Bye A. The strategic and tactical value of a 3D geotechnical model for mining optimization, Anglo Platinum, Sandsloot open pit Journal of the Southern African Institute of Mining and Metallurgy, 2006, vol. 106, no. 2, pp. 97-104.

7. Esen S., LaRosa D., Dance A., Valery W., Jankovic A. Integration and optimisation of Blasting and Comminution Processes. EXPLO. Australia, 2007. pp. 95-103.

8. Ballantyne G.R., Powell M.S. Benchmarking comminution energy consumption for the processing of copper and gold ores. Minerals Engineering, 2014, vol. 65, pp. 109-114.

9. Curry J.A., Ismay M.J.L., Jameson G.J. Mine operating costs and the potential impacts of energy and grinding. Minerals Engineering, 2014, vol. 56, pp. 70-80.
10. Abbaspour H., Drebenstedt C., Badroddin M., Maghaminik A. Optimized design of drilling and blasting operations in open pit mines under technical and economic uncertainties by system dynamic modelling. International Journal of Mining Science and Technology, 2018, vol. 28, pp. 839-848.

11. Esen S. Fragmentation modelling and the effects of ROM fragmentation on comminution circuits. $23^{\text {rd }}$ International Mining Congress \& Exhibition. Turkey, 2013. pp. 252-260.

12. Esen $\mathrm{S}$. Evaluating the fragmentation data from copper and gold mines. $43^{\text {rd }}$ Annual Conference on Explosives \& Blasting Technique. Florida, 2017. pp. 1-13.

13. Bachramov B., Myrzakasymov B., Kalmatayev A., Esen S. Improving final wall and waste blasting results at altynalmas Pustynnoye gold mine. IMCET 2019 - Proceedings of the $26^{\text {th }}$ International Mining Congress and Exhibition. Turkey, 2019. pp. 391-398.

14. Reple A., Chieregati A.C., Valery W., Prati F. Bulk ore sorting cut-off estimation methodology: Phu Kham Mine case study. Minerals Engineering, 2020, vol. 149, pp. 1-4

15. Valery W., Duffy K., Holtham P., Reple A., Walker P., Rosario P. Techno-economic evaluation of bulk ore sorting for copper ore at the panaust phu kham operation. IMPC $2016-28^{\text {th }}$ International Mineral Processing Congress. Canada, 2016. pp. 1-11.

16. Valery W., Rybinski E. Optimization process at antamina boosts production and energy efficiency. Engineering and Mining Journal, 2015, vol. 213, pp. 116-120.

17. Brent G., Dare-Bryan P., Hawke S., Rothery M. Ultra-highintensity blasting - a new paradigm in mining. AusIMM Bulletin, 2014, vol. 5, 395-400.

18. Brent G.F., Rothery M.D., Dare-Bryan P.C., Hawke S.J., Gomez R., Humeres I. Ultra-high intensity blasting for improved ore comminution. Proceedings of the $10^{\text {ih }}$ International Symposium on Rock Fragmentation by Blasting. India, 2013. pp. 163-169. 
19. Workman L., Eloranta J. The effects of blasting on crushing and grinding efficiency and energy consumption. Proceedings of the Annual Conference on Explosives and Blasting Technique. USA, 2003. pp. 131-140.

20. Couceiro P., Santos B. The influence of blasting energy factor on the loading performance. International journal of engineering research \& technology (IJERT), 2019, vol. 8, pp. 731-734.

21. Wallace G., Morton D. High energy bulk explosives and mine to mill focus - the Mt Rawdon Story. Proceedings Ninth AusIMM Open Pit Operators' Conference. Australia, 2016. pp. 60-69.

22. Isokangas E., Valery W., Jankovic A., Sönmez B. Using process integration \& optimization to provide integrated process solutions for mining operations, from mine to mill. $26^{\text {th }}$ International Mineral Processing Congress. India, 2012. pp. 2224-2234.

23. Safronov M. Uni Tronic ${ }^{\mathrm{TM}}$ dlya BVR. Kak sdelat burovzryvnye raboty bolee effektivnymi [Uni Tronic for drilling and blasting. How to make drilling and blasting more efficient]. Journal Globus, 2020, vol. 60, pp. 180-182.

24. Kuznetsov V.A. Prognozirovanie gransostava vzorvannoy massy na osnove strukturno-deformatsionnogo zonirovaniya vzryvayemykh poligonov [Prediction of the particle size distribution of the blasted mass based on the structural-deformation zoning of the blasted landfills]. Vzryvnoe delo, 2001, vol. 93. pp. 47-55.

25. Belin V.A., Potresov D.K., Sapozhnikov S.I. Optimizatsiya pokazateley proizvodstva vzryvnykh rabot na karerakh [Optimization production indicators of blasting operations in open pits]. Gorny informatsionno-analiticheskiy byulleten, 2007, no. S7, pp. 89-97.

26. Ekvist B.V. Optimization of blasting operations in the destruction of heterogeneous massifs. Gorny informatsionno-analiticheskiy byulleten (nauchno-tekhnicheskij zhurnal), 2017, no. 2, pp. 376-383. In Rus.

27. Rakhmanov R.A. Improving the technology of drilling and blasting operations during crushing of different-strength rock massifs. Gorny informatsionno-analiticheskiy byulleten (nauchnotekhnicheskiy zhurnal), 2015, no. S1-1, pp.453-465. In Rus.

28. Norov Yu.D., Bibik I.P., Zairov Sh.Sh. Management of effective parameters of drilling and blasting operations according to the quality criterion of blasted rock mass. Izvestiya vysshikh uchebnykh zavedeniy. Gorny zhurnal, 2016, no. 1, pp. 87-93. In Rus.

29. Tangayev I.A. Burimost $i$ vzryvaemost gornykh porod [Drillability and explosiveness of rocks]. Moscow, Nedra Publ., 1978. 184 p.

30. Ringwald J.P., Brawner C.O. Reinforcing concrete model pillars with grouted rock bolts. Mining Science and Technology, 1989, vol. 8, pp. 31-47.

31. Kovalenko V.A., Tangayev I.A. Energeticheskiy printsip kontrolya i optimizatsii tekhnologicheskikh protsessov na karyerakh [Energy control principle and optimization of technological processes in open pits]. Gorny informatsionno-analiticheskiy byulleten, 2008, vol. 10, pp. 293-301.

32. Kovalenko V.A. Automated preparation of production in quarries. Vestnik KRSU, 2009, vol. 9, no. 11, pp.118-123. In Rus.

33. Artemyev V.B., Kovalenko V.A., Opanasenko P.I., Isaychenkov A.B. Sovremennye informatsionnye tekhnologii $\mathrm{v}$ podgotovke $\mathrm{i}$ provedenii BVR na ugolnykh razrezakh SUEK [Modern information technologies in preparation and conduction of blasting operations at SUEK coal mines]. Ugol, 2012, vol. 11, pp. 6-13.

34. Opanasenko P.I., Isaychenkov A.B. The results of the application of the Blast Maker software and technological complex for the blasting design at the Tugnuisky open-pit mine. Gorny informatsionno-analiticheskiy byulleten (naychno-tehnicheskiy zhurnal), 2013, vol. 2, pp. 38-57. In Rus.

35. Isheyskiy V., Sanchidrián J.A. Prospects of applying MWD technology for quality management of drilling and blasting operations at mining enterprises. Minerals, 2020, vol. 10. pp. 1-17.

36. Navarro J., Schunnesson H., Ghosh R., Segarra P., Johansson D., Sanchidrián J.Á. Application of drill-monitoring for chargeability assessment in sublevel caving. International Journal of Rock Mechanics and Mining Sciences, 2019, vol. 119, pp. 180-192.

37. Vinogradov Yu.I. Invariantny metod rascheta parametrov BVR na zadanny granulometricheskiy sostav vzorvannoy gornoy massy
[An invariant method for calculating the blasting design for a particle-size distribution of the blasted rock mass]. Kremenchuk, 2010, vol. 5, pp. 97-107.

38. Vinogradov Yu.I., Grinberg I.N., Makaryev V.P., Prokopova V.G., Deev E.A. Opredelenie optimalnoy stepeni drobleniya pri perekhode na tsiklichno-potochnuyu tekhnologiyu v usloviyakh Olenegorskogo GOKa [Determination of the optimal degree of crushing when switching to cyclic-flow technology in the conditions of the Olenegorsk MPP]. Gorny zhurnal, 1976, vol. 7, pp. 28-31.

39. Belin V.A., Gorbonos M.G., Mitkov V.E. Influence of the quality of explosives and initiating systems on the efficiency of rock crushing by the explosion. Mining informational and analytical bulletin, 2016, no. S1, pp. 72-80. In Rus.

40. Overchenko M.N., Tolstunov S.A., Mozer S.P. Influence of mining-geological conditions and technogenic factors on blastholes stability during open mining of apatite-nepheline ores. Journal of Mining Institute, 2018, vol. 231, pp. 239-244.

41. Tokarenko A., Timofeyev I., Kilin S., Valery W., Valle R., Duffy K. Increasing production at polyus gold Blagodatnoye with holistic optimization from mine-to-plant. Procemin 2017: $13^{\text {th }}$ International Mineral Processing Conference. Chile, 2017. pp. 1-9.

42. Valery W., Duffy K., Faveere R., Hayashida R., Jankovic A., Tabosa E., Yelkin I. Improving profitability, sustainability and the overall operating efficiency from mine to process in Russian operations. IMPC $2018-29^{\text {th }}$ International Mineral Processing Congress. Russia, 2018. pp. 1346-1354.

43. Belyayev A.G. Experience of LLC «Azot-Chernigovets»: use of DAVEYTRONIC Electronic Blast Systems in Mining Facilities. Ugol, 2013, no. 10. pp. 4-9.

44. Kondratyev A.S., Martynushkin E.A., Bazhenov V.E. Experience of using electronic detonators EDEZ-s in the conditions of OOO «Resource» and $\mathrm{OOO}$ «Invest-Uglesbyt». Vzryvnoe delo, 2020, no. 129-86, pp. 105-115. In Rus.

45. Masaev Yu.A., Domanov V.P. Elektrodetonatory s elektronnym zamedleniem (opyt promyshlennogo primeneniya) [Electric detonators with electronic timing (experience of industrial application]. Vestnik Kuzbasskogo gosudarstvennogo tekhnicheskogo universiteta, 2010, no. 2 (78), pp.102-106.

46. Oparin V.N., Yushkin V.F., Grishin A.N., Bogatyrev A.V., Porokhovsky N.N., Rublev D.E. On promising directions of using experimental data of seismic-deformation monitoring in drilling and blasting operations in open pits. Gorny informatsionnoanaliticheskiy byulleten (nauchno-tekhnicheskiy zhurnal), 2019, no. 7, pp. 104-122. In Rus.

47. Kondrat'ev S.A., Pozdnyakov S.A., Ivanov A.S., Vandakurov K.A. Sovremennye sredstva initsiirovaniya AO «NMZ "Iskra"» [Modern means of initiation of JSC «NMZ "Iskra"»]. Vzryvnoe delo, 2019, no. 123-80, pp. 136-143.

48. Belin V.A., Gorbonos M.G., Mangush S.K., Ekvist B.V. New technologies for blasting operations. Gorny informatsionnoanaliticheskiy byulleten (nauchno-tekhnicheskiy zhurnal), 2015, no. S1, pp. 87-102. In Rus.

49. Belin V.A., Gorbonos M.G., Astakhov E.O. Vliyanie sredstv initsiirovaniya na effektivnost i bezopasnost vzryvnykh rabot [Influence of initiation means on the efficiency and safety of blasting operations]. Gorny zhurnal, 2017, no. 7, pp. 63-67.

50. Sysoev A.A., Kondratev S.A., Katanov I.B. Comparative evaluation of pyrotechnic and electronic blasting caps on the basis of a probabilistic model of initiation of a borehole charge system. Vzryvnoe delo, 2020, no. 126-83, pp. 85-98. In Rus.

51. Mityushkin Yu.A., Lysak Yu.A., Plotnikov A.Yu., Ruzhitsky A.V., Shevkun E.B., Leshchinsky A.V. Optimization of blasting parameters by increasing spacing intervals. Gorny informatsionnoanaliticheskiy byulleten (nauchno-tekhnicheskiy zhurnal), 2015, no. 4, pp. 341-348. In Rus.

Received: 26 April 2021.

\section{Information about the authors}

Mikhail A. Marinin, Cand. Sc., associate professor, Saint-Petersburg Mining University.

Matvey V. Evgrafov, postgraduate student, Saint-Petersburg Mining University.

Vadim V. Dolzhikov, Cand. Sc., associate professor, Saint-Petersburg Mining University. 